\title{
Evaluation of Resistance Type SFCL on Reduction of Destructive Effects of Voltage Sag on Synchronous Machine Stability
}

\author{
Behrouz Alfi ${ }^{1}$, Tohid Banki ${ }^{2}$, Faramarz Faghihi $^{3}$ \\ ${ }^{1}$ Department of Electrical Engineering College of Engineering Ardabil Branch, Islamic Azad University, Ardabil, Iran \\ ${ }^{2}$ Department of Electrical Engineering College of Engineering Bilasouvar Branch, Islamic Azad University, Bilasouvar, Iran \\ ${ }^{3}$ Department of Electrical Engineering College of Engineering Science and Research Branch, Islamic Azad University, Tehran, Iran
}

\section{Email address:}

beh_alfi@yahoo.com (B. Alfi), tohidbanki@gmail.com (T. Banki), faramarz_faghihi@hotmail.com (F. Faghihi)

\section{To cite this article:}

Behrouz-Alfi, Tohid- Banki, Faramarz- Faghihi. Evaluation of Resistance Type SFCL on Reduction of Destructive Effects of Voltage Sag on Synchronous Machine Stability. Journal of Electrical and Electronic Engineering. Vol. 3, No. 6, 2015, pp. 187-191.

doi: $10.11648 /$ j.jeee.20150306.12

\begin{abstract}
Electrical power quality has become an essential part of power systems and electrical machines. True identifying and regarding power quality and how to check the related destructive points are of utmost importance. Most of the time, providing the quality of power for sensitive load which requires the voltage to maintain a sinusoidal waveform at rated voltage and frequency is the main point to be considered. On the other hand, protecting power supply against resulting turbulences can be regarded. Voltage sag is one of the destructive issues in power quality problem to be taken into account. Not only can it have some undesirable effects on the sensitive load, but it also has some undesirable effects on synchronous machine as a power supply. In this study, SFCL was used in order to reduce the destructive effects of voltage sag on the performance of synchronous generators. To achieve better understanding, a simple model composed of synchronous generators, SFCL and load is used with the help of MATLAB/SIMULINK software. By creating voltage sag which results from 3-phase short-circuit voltage, current, torque, speed and angle load changes of synchronous generators were simulated and discussed. It was done in condition with/without SFCL. The results illustrate that using SFCL in synchronous generator output can improve its performance during occurrence of voltage sag.
\end{abstract}

Keywords: Superconducting Fault Current Limiters (SFCL), Synchronous Machine, Power Quality, Voltage Sag

\section{Introduction}

The importance of paying attention to power quality issue is increasing day by day. Power quality is usually meant to say the quality of voltage and/or the quality of current and can be defined as: the measure, analysis, and enhancement of the bus voltage to keep a sinusoidal waveform at rated voltage and frequency [1]. Nowadays, voltage sag is the main problem for huge industries and has the most pressure on power quality.

Sags are short-duration reduction in the rms voltage between 0.1 and 0.9 for the duration between 0.5 cycles and 1 minute. It is also divided into instant, momentary and temporary types to continuing time. Voltage sags are usually caused by: energization of heavy loads, starting of large induction motor and one/two/three-short circuit faults. More need for electric power results while increasing the level of short-circuit current which makes electric equipment fail and it is because of the resulting mechanic and electric pressure.

One common way for limiting fault current with high level is using fault current limiter (FCL). FCL is fundamentally a variable resistance that is set up serially in circuit with breaker. When a fault occurs, impedance increases to an amount in which the fault current decreases to an amount with a low level as much as the breaker can undergo it. FCL efficiency in limiting short-circuit fault makes it possible for breakers to open easily and safely. The function of FCL in electric power systems is both limiting the range of short circuit currents and increasing the stability level of power system. By developing electronic power magnetic technology and superconductors, fault current limiters are developed [2-6]. Among the mentioned cases, SFCL is suggested for limiting fault current. SFCL can be a good solution for controlling fault current levels in 
distribution and transmission networks and it is due to less losses in normal function of superconductors [7-9]. The coordination of SFCL as a key application issue has been investigated in previous papers $[10,11]$. When a fault occurs, SFCL produces impedance and it is because of the loss of superconductor. It puts this impedance on the circuit which limits fault current. Therefore, SFCLs which have characteristics of superconductors can change the level of resistance from near zero (superconductor state) to high level in normal state (non-superconductor state) [12]. It is the case when current, temperature or field outreach critical amount. These kinds of limiters do not need fault recognition system; therefore, their reaction (response) is quick. Voltage sags cause apart eventual triping, large torque peak, which may cause damage to the shaft or equipment connected to the shaft. During voltage sags, the behavior of synchronous machines is explained and why there are high torque and current peak during voltage sags and approach is presented in the use of quick breaker [13]. In this study, SFCL was used in order to reduce the destructive effects of voltage sag on the performance of synchronous generators.

\section{Torque and Current Formulation of Synchronous Machine}

Due to the creation of peak current and huge torque, voltage sag can damage shaft or lateral equipments of synchronous machines. Stator flux, which is dependent on the time during voltage sag, explains the action of synchronous machines and the reason for emerging huge peak current and torque. Torque equation in steady state is defined as equation (1). According to this equation, torque is proportional to stator flux; if the flux is doubled, the torque will be more than twice.

$$
T=P\left\{\frac{\psi_{s} \psi_{d f}}{L_{d}} \operatorname{Sin} \delta+\psi_{s}^{2} \times\left(\frac{1}{L_{d}}-\frac{1}{L_{q}}\right) \operatorname{Sin} 2 \delta\right\}
$$

As well as, current equation in the terminal synchronous generator in temporary state is defined as equation (2).

$$
\begin{gathered}
i_{a s}=\frac{\sqrt{2}}{2 \omega} V_{S}\left[\frac{1}{L_{d}}+\frac{1}{L_{q}}\right] e^{-\alpha t} \operatorname{Sin}\left(\theta_{r}(0)\right) \\
i_{b s}=\frac{\sqrt{2}}{2 \omega} V_{S}\left[\frac{1}{L_{d}}+\frac{1}{L_{q}}\right] e^{-\alpha t} \operatorname{Sin}\left(\theta_{r}(0)-120\right) \\
i_{a s}=\frac{\sqrt{2}}{2 \omega} V_{S}\left[\frac{1}{L_{d}}+\frac{1}{L_{q}}\right] e^{-\alpha t} \operatorname{Sin}\left(\theta_{r}(0)+120\right)
\end{gathered}
$$

In temporary condition $L_{d}^{\prime}$ is replaced $L_{d}(\mathrm{~d}$ axis inductance), the torque and current in temporary condition will be more because of $L_{d}^{\prime} \ll L_{d}$. The effect of $\delta$ (load angle) on torque will be less because of few changes. According to equation (2), current in all three phase synchronous generator in temporary condition will increase.

\section{Resistance Type SFCL}

Critical current density $\left(J_{c}\right)$ is one of the main parameters in superconductors. Increasing the current to more than $J_{c}$ level can lead to the changing state of matter from being superconductor to normal state. Therefore, the current which passes through superconductor can resist controlling factor. One problem in conventional fault current limiter is fault recognition system. That is, it should be able to limit the fault current at the first period and before reaching the first peak. One advantage of superconductor limiters is that they do not need fault recognition system. By sudden increase in network current level which is due to fault, the current which passes through limiters traverses from critical current and so the limiter takes impedance and limits the fault current. In most case, voltage sag is temporary and can be removed immediately. Applying SFCL avoids bad effects of voltage sag. In addition, the load which makes financial losses for huge industries can be kept safe. SFCL has been proposed to limit the short circuit current and various types of SFCLs have been developed. SFCLs are of different types including saturated iron core reactor type, bridge type, flux lock type, reactor and resistance type. Equation (3) shows voltage drop in SFCLs in the superconducting state, flux flow state and normal state:

$$
U_{S}=\left\{\begin{array}{c}
0 \text { if }\left|i_{s}\right| \leq i_{c}(t), T<T_{c} \\
R_{P}\left[i_{s}-\operatorname{sign}\left(i_{s}\right) i_{c}(t)\right] \text { if }\left|i_{s}\right|>i_{c}(t), T<T_{c} \\
R_{n} i_{s} \text { if } T \geq T_{c}
\end{array}\right.
$$

In the above equation, $R_{p}$ is the highest limiter resistance in normal condition. Moreover the dominant temperature is $77^{\circ} \mathrm{K}$. The model which was suggested in this study is 3phase resistance type placed in a synchronous generator output. Fig. 1 shows the resistance type of SFCL. In this study, for simulating the condition, it was suggested that at fault moment the highest level of resistance be inserted in the line and after removing the fault, it should reach the zero level in the superconductor phase.

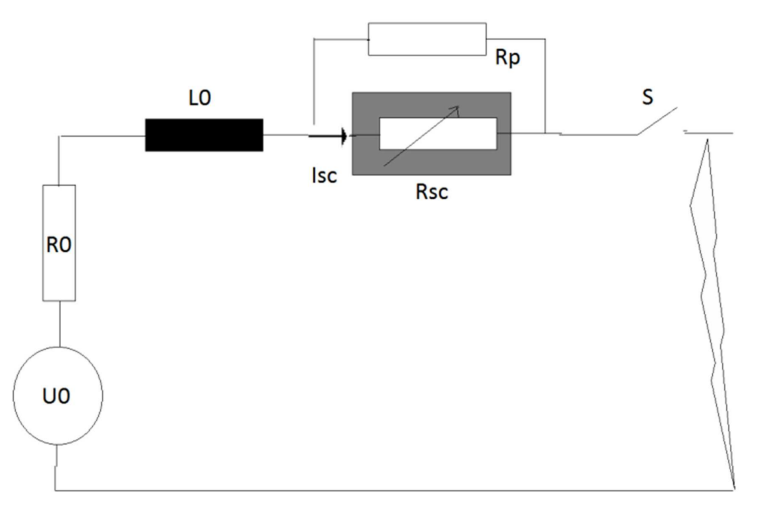

Fig. 1. Resistance Type of SFCL [4].

\section{Result of Voltage Sag Effect on Synchronous Generator}

Fig. 2 shows the single-line diagram of the discussed model. The simulation was done by MATLAB/SIMULINK 
software. This model includes a synchronous generator, resistance type SFCL, and load with constant power. In order to create voltage sag, 3-phase short circuit was done according to Fig. 3. Increasing peak current and torque may become 10 times more which can damage shaft or lateral equipment. Time of 1 second was selected for simulation time duration and 0.1 second was selected for voltage sag duration. Therefore, 3 -phase short circuit occurred 0.7 second and the fault was removed after 0.1 second.

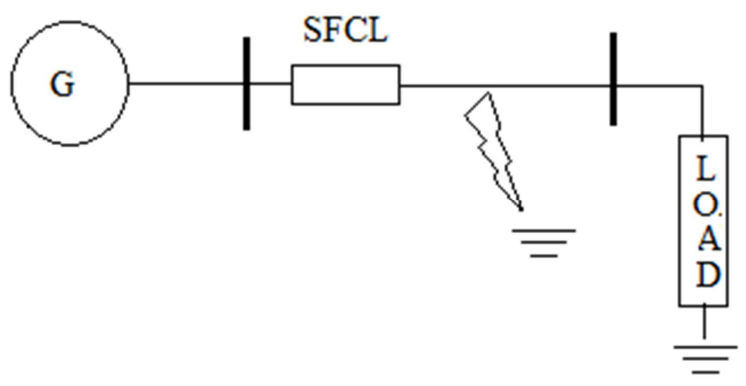

Fig. 2. Single-Line Diagram of the Model Using SFCL.
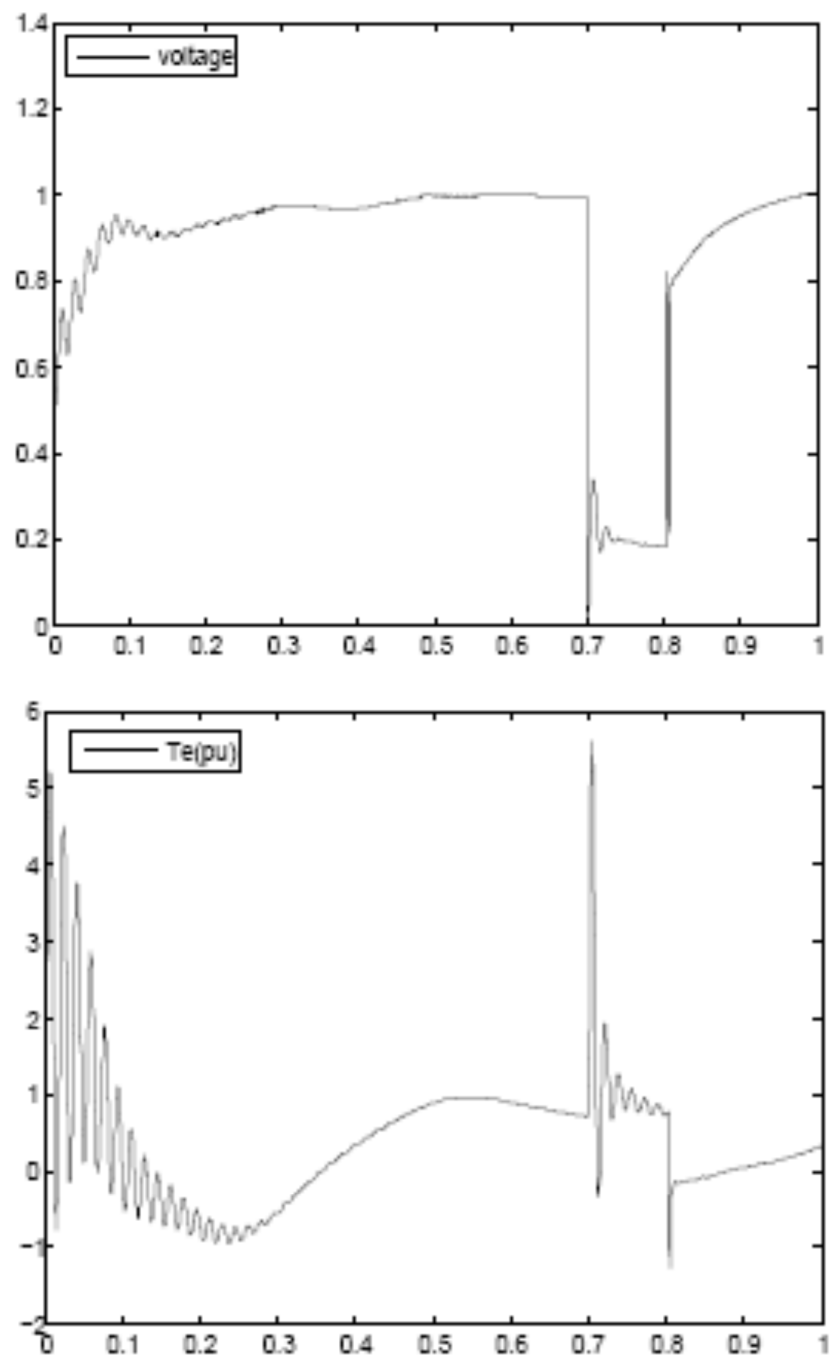
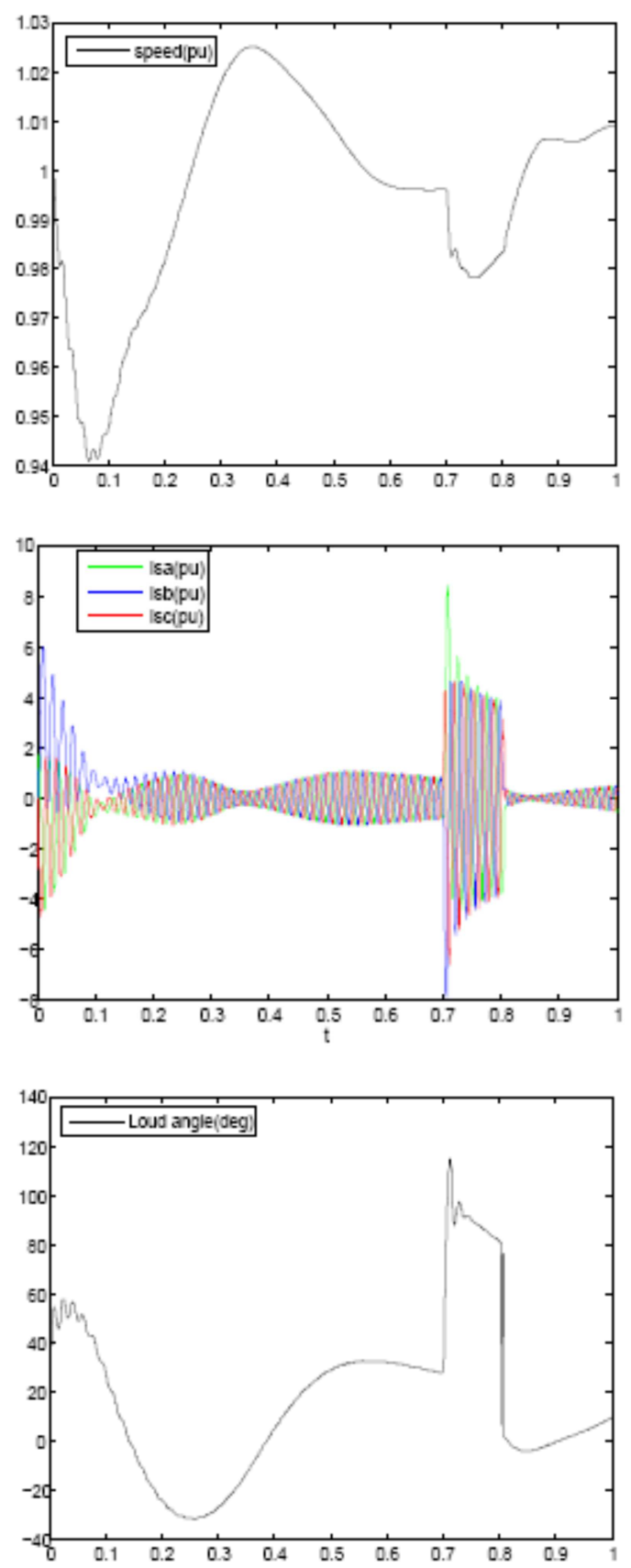

Fig. 3. Voltage, Current, Torque, Speed and Load Angle due to Voltage Sag without SFCL.

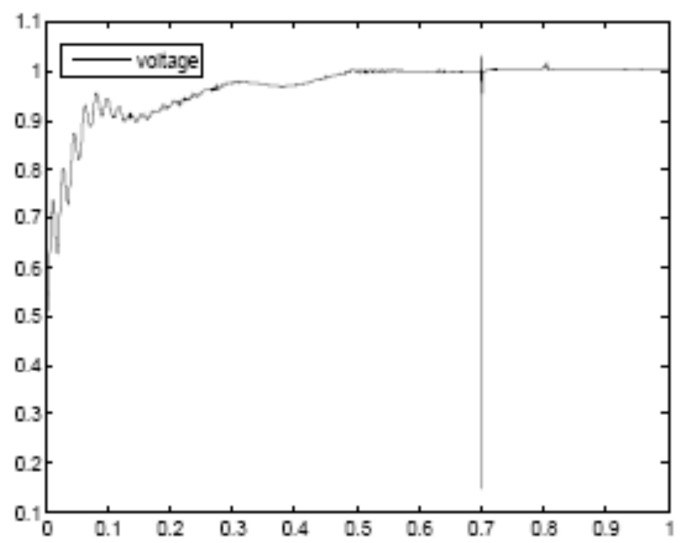



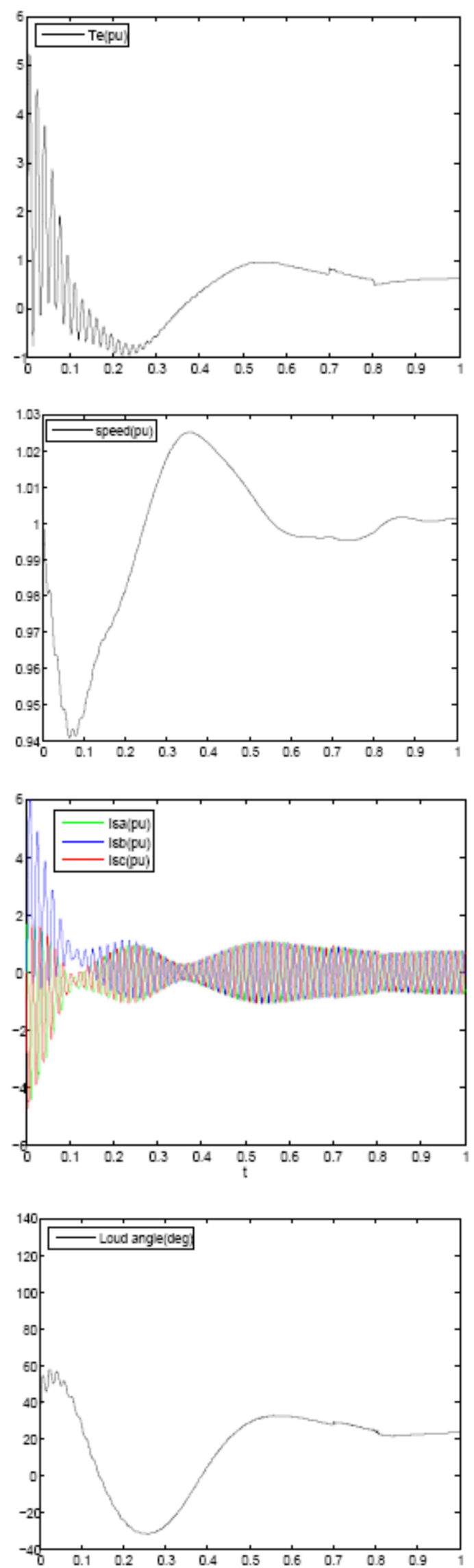

Fig. 4. Voltage, Current, Torque, Speed and Load Angle due to Voltage Sag with SFCL.
The simulation was done through two steps and voltage, current, speed, load angel and torque change results were reported in this study. At first step, voltage sag was shortduration in the rms voltage $0.2 \mathrm{pu}$, and it was without SFCL, as shown in Fig. 4. It is shown in Fig. 4 that the voltage sag has led to an increase in peak current, torque, load angle and decreasing speed. These changes were at their high level at the time of short circuit. In the second step, the fault occurred along with SFCL. In this condition, SFCL turned from superconductor phase into normal phase. Along with increasing line resistance, SFCL avoided increasing torque and current peak.

\section{Conclusion}

The SFCL has been used and implemented in this paper using MATLAB/SIMULINK software. SFCL can react to created turbulences immediately and avoid bad effects of voltage sag on synchronous generator such as increasing torque and current in fault period and it can stabilize generator system during a severe fault.

\section{References}

[1] Ewald F. Fuchs, Mohamad A. S. Masoum, "Power Quality in Power Systems and Electrical Machines," Elsevier Inc, ISBN 978-12-369536-9, 2008.

[2] R. F. Giese, et al, "Assessment Study of Superconducting Fault Current Limiters Operation at $77 \mathrm{~K}$," IEEE Transactions on Power Delivery, Vol.8, No. 3, pp. 1138-1147, July 1993.

[3] R. Smith et al., "Solid State Distribution Current Limiter and Circuit Breaker Application Requirements and Control Strategies," IEEE Transactions on Power Delivery, Vol. 8, No. 3, pp. 1155-1164, July 1993.

[4] V. Hassenzahi, K. Johnson, T. Reis, "Electric Power Application of Superconductivity," proceeding of the IEEE, V. 92, No. 10, Oct 2004.

[5] E. Thuries, et al., "Toward the Superconducting Fault Current Limiter," IEEE Transactions on Power Delivery, Vol. 6, pp. 801-808, April 1991.

[6] M. Chen, et al., "Fabrication and Characterization of Superconducting rings for Fault Current Limiter Application," IEEE Transaction on Applied superconductivity, Vol. 282287, pp. 2639-2642, 1997.

[7] L. Ye, L. Z. Lin, and K. P. Juengst, "Application Studies of Superconducting Fault Current Limiter in Electric Power Systems," IEEE Transactions on Applied Super-conductivity, Vol.12, No.1, pp. 900-903, March 2002.

[8] K. Hongesombut, "optimal location assignment and design of superconducting fault current limiter applied to loop power system”, IEEE, Vol. 13, No. 2, 2003.

[9] J. S. Kim, S. H. Lim, and J. C. Kim, "Study On Protection Coordination Of Flux-lock Type SFCL with Over-current Relay," IEEE Transactions on Applied Super- conductivity, Vol. 20, No. 3, June 2010. 
[10] S. Kazemia, M. Lehtoneb, "Impact of Smart Sub-transmission Level Fault Current Mitigation Solutions On Service Reliability," Electric Power System Research, Vol. 96, pp. 915, Mar 2013.

[11] B. Li, C. Li, F. Guo, "Coordination Superconductive Fault Current Limiters with Zero-sequence Current Protection Of Transmission Lines," IEEE Transactions on Applied Superconductivity, Vol. 24, No. 5, pp. 5602105, Oct 2014.
[12] B. Li, C.Li, F. Guo, "Over Current Protection Coordination in a Power Distribution Network with Active Superconductive Fault Current Limiters," IEEE Transactions on Applied Super-conductivity, Vol. 24, No. 5, pp. 5602004, Oct 2014.

[13] F. Carlsson, Ch. Sadarangani, "Behavior of Synchronous Machines Subjected to Voltage Sags of Type A, B and E", EPE journal. Vol.15, 2005. 